\title{
Distribution of heavy metals in anthropogenic soils: on the example of the industrial zone of Moscow
}

\author{
Elena Latushkina ${ }^{1}$ and Anna Oleynik $^{2}$ \\ ${ }^{1}$ Russian State Social University, 4/1, Wilhelma Pika St., Moscow, 129226 Russia \\ ${ }^{2}$ Peoples' Friendship University of Russia (RUDN University), Faculty of Ecology, 6 Miklukho- \\ Maklaya St, Moscow, 117198, Russian Federation
}

\begin{abstract}
The article presents the results of the assessment of the distribution of heavy metals content in anthropogenic transformed soils of the industrial zone of Moscow. Excesses of norms are shown, geochemical associations are obtained. The work proved to exceed the maximum permissible concentrations of cadmium, lead, copper, nickel, zinc, arsenic for eleven test sites per 13.95 hectares of industrial zone in 57\% of the obtained empirical data on the content of pollutants in the soil. In the investigated area, the contents of lead, copper, nickel and zinc are not uniformly distributed and are within wide range. No excess of the norm was recorded for mercury. The isolation of two geochemical associations of manmade genesis is justified. One association includes cadmium lead, copper, and zinc with the system-forming element copper. The other consists of nickel and mercury.
\end{abstract}

\section{Introduction}

Heavy metals participation in biogeochemical cycles, their toxicity, the ability to form geochemical associations, accumulate and transform the qualities of environmental components together with insufficient study of their behaviour in the biosphere determine the relevance of studies on the distribution assessment of heavy metals in environmental elements. In works of many authors it has been proved: "Soils are the depositing medium for heavy metals" $[1,2,3,4]$. In cities, especially in industrial zones, special, anthropogenic changed soils have been formed characterized by increased content of ecotoxicants [3].

Industrial areas where economic activities have ceased are usually in need of recultivation. Depending on the level of soil contamination, the algorithm, methods and technologies for the restoration of industrial areas will depend.

Contamination of soils by heavy metals in industrial areas of urban agglomerations has a negative impact on public health. This is due to the wind transfer of dust from the soil surface and its ingress into the human respiratory system and on the skin surface [7]. Heavy metals have been proven to have toxic, allergic, carcinogenic, gonadotropic effects. Among the elements with toxic effects on human health, cadmium, copper, arsenic, nickel, mercury, lead, zinc are accepted [8]. 


\section{Materials and methods}

The study was carried out during the summer period of 2019 on the territory of the former industrial zone located on a plot of 13.95 hectares at the intersection of the Enthusiasts Highway and the Nizhny Novgorod trestle. There has been no economic activity in this territory for several years.

Soil samples were collected in accordance with the principles of uniformity of placement and availability of physical accessibility of test sites. A total of 11 sites were designated for soil sampling, with 11 average samples taken. Sampling was performed in accordance with the requirements of state standards $[9,10]$.

Each sample was signed and delivered to the accredited laboratory of ANO "Independent Institute of Expertise and Standardization" to determine the content of lead, zinc, copper, nickel, cadmium, arsenic, and mercury by atomic absorption spectrometry and spectrophotometry.

The content of lead, zinc, copper, nickel, and cadmium was revealed by using an atomic and absorbing spectrometer of AAS-30. Arsenic was measured spectrophotometrically on the SF-26 spectrophotometer. The mercury content was determined by the flame-free atomic absorption method on the "Julia-2" mercury analyzer.

The analysis of the obtained empirical data was carried out using the index method, the descriptive mathematical statistics (arithmetic mean, minimum and maximum value, range), correlation analysis, correlation arm method.

\section{Results and discussion}

Exceeding of the maximum permissible concentration (MPC) of heavy metals in the soils in of the test areas is given in Table 1.

Table 1. Excess of MPC of heavy metals in soils

\begin{tabular}{|c|c|c|c|c|c|c|c|}
\hline \multirow{2}{*}{$\begin{array}{c}\text { Sample } \\
\text { number }\end{array}$} & \multicolumn{7}{|c|}{ Chemical element } \\
\cline { 2 - 8 } & $\mathbf{C d}$ & $\mathbf{P b}$ & $\mathbf{C u}$ & $\mathbf{N i}$ & $\mathbf{Z n}$ & $\mathbf{A s}$ & $\mathbf{H g}$ \\
\hline 1 & 1.0 & 2.6 & 10.7 & 9.7 & 4.2 & 0.7 & 0.01 \\
\hline 2 & 2.1 & 3.7 & 8.5 & 4.9 & 3.0 & 0.5 & $<0.01$ \\
\hline 3 & 0.7 & 0.8 & 4.3 & 4.9 & 1.5 & 0.5 & $<0.01$ \\
\hline 4 & 0.8 & 1.0 & 4.8 & 4.1 & 1.6 & 0.4 & $<0.01$ \\
\hline 5 & 0.5 & 0.1 & 16.1 & 2.8 & 1.4 & 0.6 & $<0.01$ \\
\hline 6 & 0.7 & 0.3 & 3.5 & 2.8 & 2.3 & 0.8 & $<0.01$ \\
\hline 7 & 0.8 & 2.7 & 14.6 & 9.3 & 6.0 & 1.0 & $<0.01$ \\
\hline 8 & 0.3 & 6.2 & 13.4 & 2.8 & 5.3 & 0.7 & $<0.01$ \\
\hline 9 & 1.6 & 11.9 & 23.3 & 5.0 & 6.6 & 0.5 & $<0.01$ \\
\hline 10 & 1.5 & 10.6 & 29.3 & 7.5 & 12.6 & 1.6 & $<0.01$ \\
\hline 11 & 0.5 & 13.7 & 196.3 & 9.8 & 252.0 & 0.7 & 0.01 \\
\hline
\end{tabular}

It can be seen from in Table 1 that over $57 \%$ of all values obtained exceeds the norm. All samples have increased copper, nickel, and zinc content; seven samples show the excess of MPC for lead; three samples for cadmium, and one for arsenic.

Table 2 shows that the content of lead, copper, nickel, and zinc varies widely enough. This indicates uneven scattering of the pollutants on the studied site. 
Table 2. Average, minimum, maximum values of heavy metals content in anthropogenic soils and their range of variation, $\mathrm{mg} / \mathrm{kg}$

\begin{tabular}{|l|c|c|c|c|c|c|c|}
\hline \multicolumn{1}{|c|}{ Indicator } & $\mathrm{Cd}$ & $\mathrm{Pb}$ & $\mathrm{Cu}$ & $\mathrm{Ni}$ & $\mathrm{Zn}$ & $\mathrm{As}$ & $\mathrm{Hg}$ \\
\hline Average value & 0.480 & 146.13 & 88.6 & 23.13 & 619.8 & 1.47 & 0.04 \\
\hline Minimum value & 0.169 & 2.06 & 10.36 & 11.2 & 31.17 & 0.829 & $<0.02$ \\
\hline Maximum value & 0.783 & 411.3 & 589 & 39.24 & 5797.00 & 3.22 & 0.04 \\
\hline Amplitude & 0.614 & 409.24 & 578.64 & 28.04 & 5765.83 & 2.39 & 0.02 \\
\hline
\end{tabular}

To identify geochemical associations, correlation coefficients were calculated using the K. Pearson formula (Table 3), and correlation pleiades were constructed (Figure 1).

Table 3. Correlation coefficients between indicators heavy metal content in anthropogenic soils

\begin{tabular}{|c|c|c|c|c|c|c|c|}
\hline Chemical element & $\mathrm{Cd}$ & $\mathrm{Pb}$ & $\mathrm{Cu}$ & $\mathrm{Ni}$ & $\mathrm{Zn}$ & $\mathrm{As}$ & $\mathrm{Hg}$ \\
\hline $\mathrm{Cd}$ & 1.0 & & & & & & \\
\hline $\mathrm{Pb}$ & 0.2 & 1.0 & & & & & \\
\hline $\mathrm{Cu}$ & 0.7 & 0.7 & 1.0 & & & & \\
\hline $\mathrm{Ni}$ & 0.1 & 0.4 & 0.5 & 1.0 & & & \\
\hline $\mathrm{Zn}$ & -0.3 & 0.6 & 0.9 & 0.5 & 1.0 & & \\
\hline $\mathrm{As}$ & 0.1 & 0.3 & 0.1 & 0.4 & -0.1 & 1.0 & \\
\hline $\mathrm{Hg}$ & -0.1 & 0.1 & 0.3 & 0.7 & 0.4 & -0.1 & 1.0 \\
\hline
\end{tabular}

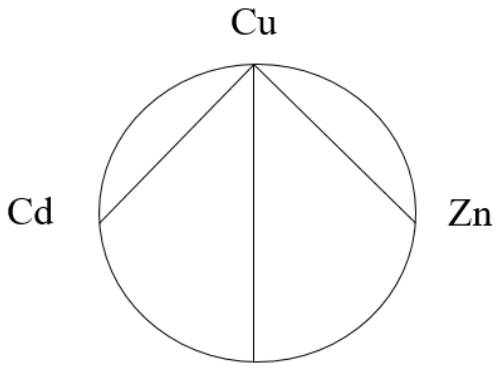

$\mathrm{Pb}$

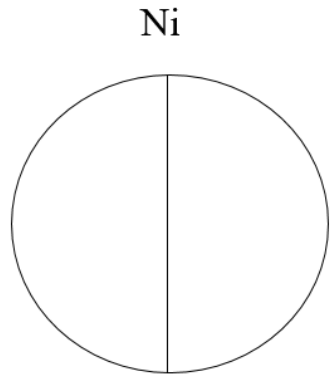

$\mathrm{Hg}$

Fig. 1. Geochemical associations of heavy metals in anthropogenic soils

The geochemical association with the binding element (copper), which unites cadmium, lead, and zinc into a single group, is characterized by a high close relationship between copper and zinc (0.9). This may be due to the use in production brass or parts of equipment made of this alloy in the production. It should be noted that lead brass is used in mechanical engineering for making fasteners and gears. The high value of the correlation coefficient between cadmium and copper may mean the use in production of cadmium bronze, which is necessary for the manufacture of collector plates, contact wires of electrified transport. The presence of lead in the soil is due to its presence in the exhaust gases of road transport passing near the research site on the roads of the city.

The geochemical association of nickel and mercury with the close relationship of elements, which is 0.7 indicates the joint application of these chemical elements in the analysed industrial zone. It can be using or amalgam obtaining required for electrical engineering.

The revealed peculiarities of distribution of heavy metals in the decommissioned industrial zone located in the immediate vicinity of roads and residential buildings indicate the need to carry out recultivation measures. 
Practical recommendations for the environmentally sound use of a territory with a high content of heavy metals in anthropogenic soils should be:

- Soil removal and cleaning;

- Creation of a reclamation layer, replacement or dilution of the contaminated soil layer;

- Control of chemical element ratios in soil;

- Planting of herbs or roll lawn flooring;

- Planting of plants resistant to increased content of heavy metals.

\section{Conclusion}

In the territory of the former industrial zone where there is no economic activity for a long time heavy metals are:

- not uniformly distributed in the soil, variations in lead, copper, nickel and zinc are within wide limits, the standards for cadmium, lead, copper, nickel, zinc and arsenic are exceeded. At all points the run-up exceeding the maximum permissible concentration is recorded by copper, nickel, and zinc;

- Form two geochemical associations. The first is represented by cadmium, lead and zinc with the system-forming element copper. The second is nickel and mercury. The genesis of these associations is man-made.

\section{References}

1. N.A. Kirpichnikov, N.A Chernykh, I.N. Chernykh, Agrochemistry, 2, 93-101 (1993) (in Russian)

2. E.V. Stanis, E.N. Latushkina, N.V. Marsheva, E.A. Parakhina, Problems of regional ecology, 2, 109-112 (2018) (In Russian)

3. G.A. Warm, Astrakhan J. of Environmental Education, 1 (23), 182-192 (2013)

4. D.V. Vlasov, Geophysical Research, Abstracts, 16 (2014).

5. N.S. Kasimov, D.V. Vlasov, N.E. Kosseleva, E.M. Nikiforova, Geochemistry of landscapes of Eastern Moscow (APR, Moscow, 2016)

6. I.F., Medvedev, S.S. Zhelyagin, Heavy metals in ecosystems ("Racurs" Publ., Saratov.) (2017) (In Russian)

7. I.V. Wise, Hygiene and sanitation, 4, 32-37 (2008)

8. M.I. Chubirko, Population Health and Habitat, 1, 19-20 (2008)

9. GOST 17.4.3.01-2017 Nature Protection. Soils. General sampling requirements (in Russian)

10. GOST 17.4.4.02-2017 Nature Protection. Soils. Methods of sampling and preparation of samples for chemical, bacteriological, helminthological analysis (In Russian) 